\title{
THE INTERPRETIVE PARADIGM IN FINANCE RESEARCH: AN OVERVIEW OF BEHAVIORAL FINANCE
}

\author{
Darman*, Salim Ubud, Aisjah Siti, Indrawati Nur Khusniyah \\ Faculty of Economics and Business, University of Brawijaya, Indonesia \\ *E-mail: darman tadulako@yahoo.com
}

\begin{abstract}
Until now, the financial research is dominated by functionalist paradigm. Whereas there are other paradigms in this world such as the radical structuralist, radical humanist, and interpretive. Particularly, in behavioral finance research, it is very relevant to use interpretive paradigm because behavioral finance explains the what, why, and how infestation works from human perspective. Interpretive paradigm is used to understand the world as it is, understand nature from the social world in subjective experience, and explain individuals and subjectivity consciously. In the future, it is expected that there is another contribution of financial studies by using other paradigms, particularly by the interpretive paradigm. Interpretive paradigm consists of several types, such as ethnomethodology, phenomenological, and symbolic interactionism. Those three types of paradigm can touch the study object that not only depends on its financial market but also on individuals, households, and others so that it has deeper, meaningful, and more diverse research results.
\end{abstract}

\section{KEY WORDS}

Finance research, behavioral finance, research paradigm, interpretive paradigm.

Recently, financial behavior has become a trending topic in terms of financial journals. As one of the behavioral finance initiators, Thaler (1993) suggested that behavioral finance is a new approach to financial markets that has emerged, at least in part, in response to the difficulties faced by the traditional paradigm. In broad terms, it argues that some financial phenomena can be better understood using models in which some agents are not fully rational. More specifically, it analyzes what happens when we relax one, or both, of the two tenets that underlie individual rationality. In some behavioral finance models, agents fail to update their beliefs correctly. In other models, agents apply Bayes's law properly but make choices that are normatively questionable, in that they are incompatible with Savage's notion of Subjective Expected Utility.

The research on financial behavior has been conducted in various parts of the world, such as Spindler (2011) on the European continent, Shiller (2003) in the American continent, and Sasongko et al. (2016) in the Asian Continent. While in general, the research revolves around the phenomenon of mainstream financial markets. Why is this happening? Whereas in October 2002, the Journal of Empirical Finance and the Limburg Institute for Financial Economics (LIFE) at the University of Maastricht jointly organized a conference on behavioral finance in Palma de Mallorca (Spain). Methodologically, behavioral finance operates at three levels: (i) it conducts experiments with subjects under controlled laboratory conditions; (ii) it studies real-world financial decisions made by individuals, households, financial professionals and corporations; and (iii) it looks into the behavior of financial markets (Editorial, 2004).

Ardalan (2003) believed that the paradigm of financial research is positioned on a continuum formed by four basic paradigms such as functionalist, interpretive, radical humanist, and radical structuralist. The hierarchical structure of this paradigm is composed of 3 levels namely paradigms, metaphors, and puzzles. It is expected that in the future, such kind of finance research that use interpretative paradigm, radical humanist, and radical structuralist could be well established. Furthermore, Muradoglu and Harvey (2012) the primary input to behavioral finance has been from experimental psychology. Methods developed within sociology such as surveys, interviews, participant observation, focus 
groups have not had the same degree of influence. Typically, these methods are even more expensive than experimental ones and so costs of using them may be one reason for their lack of impact. However, it is also possible that the training of finance academics leads them to prefer methodologies that permit greater control and a clearer causal interpretation.

Based on the opinions and those three limits and scopes, it is considered that it could help to provide research opportunities on different objects and paradigms. For examples, making in-depth observations on individuals, households, and financial professionals in financial decision-making. One of the paradigms that can be used to deeply observe a decision-making phenomenon is the interpretive paradigm.

Behavioral Finance. Theoretical and empirical research in finance proceeded as if the human factor in financial decision-making did not matter very much. Many financial economists admitted that the intuitive judgment of investors and their advisors revealed some shortcomings, but they also maintained that the forces of rational arbitrage ensured that market prices were efficient, i.e., stock prices quickly and adequately reflected all available information. The psychology of money was seen as a captivating topic but one that may well be "too interesting" for economists and that may distract them "from the pervasive market forces that should be [their] principal concern" (Miller, 1986).

This point of view is less widespread and it has become less plausible. One reason has to do with the extraordinary events of the 1980s and the 1990s. A second reason is that a new approach has emerged. Behavioral finance thinks about financial issues with the help of ideas borrowed from psychology. It not only casts doubt on the predictions of modern finance, such as the notion of efficient markets but also on its micro-foundations, i.e., expected utility maximization, rational expectations, and Bayesian updating. Prospect theory, mental frames, heuristics and related psychological concepts form the basis for a new theory of finance. Opinions differ, but so far, it appears, behavioral finance has been a fertile paradigm. In the area of asset pricing, for instance, it has been used to interpret and/or to discover empirical anomalies in the speculative dynamics of stock returns, e.g., under- and overreaction to news. Additionally, through detailed surveys and archival studies of trading behavior, a great deal has been learned about the conduct of investors, analysts, money managers, and others. In corporate finance, the behavioral approach has stimulated interest in the determinants and the quality of executive decision making, e.g., excessive risk aversion, unjustified optimism, hubris and so on (Kahneman, 2002).

Psychological factors play a role in a financial decision-making. Therefore, financial analysis that is using psychology and financial science is known as financial behavior. Thaler (1993) said that behavioral finance is simply open minded finance-claiming that sometimes in order to find the solution to an [financial] empirical puzzle it is necessary to entertain the possibility that some agents in the economy behave less than fully rationally some of the time. Lintner (1998) on the other hand proposed that behavioral finance is the study of how humans interpret and act on information to make informed investment decisions. Olsen (1998) also said that behavioral finance does not try to define "rational" behaviour or label decision making as biased or faulty; it seeks to understand and predict systematic financial market implications of psychological process. It is followed by Shefrin (2000) which defines behavior finance as a study of how psychological phenomena affect their financial behavior.

Ricciardi and Simon (2000) suggested that the key to defining behavioral finance is to first establish strong definitions for psychology, sociology and finance.

Figure 1 demonstrates the important interdisciplinary relationships that integrate behavioral finance. When studying concepts of behavioral finance, traditional finance is still the centerpiece; however, the behavioral aspects of psychology and sociology are integral catalysts within this field of study. Therefore, the person studying behavioral finance must have a basic understanding of the concepts of psychology, sociology, and finance to become acquainted with overall concepts of behavioral finance.

Tversky and Kahneman (1979) reveal that there are three factors in human behavior that are contrary to the assumptions underlying the classical economic model in decisionmaking. This phenomenon is referred to as "cognitive illusions" because it is associated with the perception that often leads to errors. 


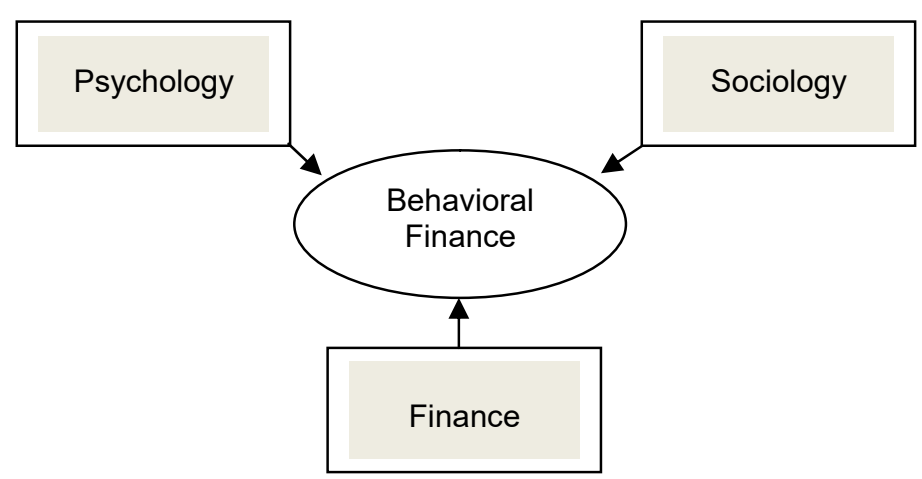

Figure 1 - Behavioral Finance among Psychology, Sociology and Finance

(Ricciardi and Simon, 2000)

1. Risk attitudes. The fundamental assumption in economic theory points out that humans are creatures that do not like risk. Investors will prefer an investment that provides a definite rate of return compared to an investment that contains uncertainty in return. There is a positive relationship between the level of risk and the level of return expected by the investor. Because investors act like they risk averse, then they are just willing to take a riskier investment opportunity if they can obtain higher profit levels.

2. Mental Accounting. This factor refers to the tendency of investors to classify their finances on different accounts based on subjective criteria such as sources of funding and the purpose of utilizing income. The allocation of different functions to each of these accounts often causes irrational impacts on financial decision-making (both in terms of expenditure and savings) in which it deviated from conventional economic concepts.

3. Overconfidence. It is undeniable that humans have a tendency to be overconfident of their ability and predictions to succeed. This condition is a normal thing that is also a mirror of a person's confidence level to achieve or get something.

Interpretive Research Paradigm. Interpretive paradigm is also known as subjective interactionist. This alternative approach comes from German philosophers who focus on the role of language, interpretation, and understanding in social sciences. This paradigm has a base thought that the rules applied in natural sciences cannot be applied to social sciences. The perspective of nominalists who see social reality as something that is only a label, a name, or a concept is used to build a reality and nothing real.

The nature of this paradigm believes that social reality is consciously and actively built by individuals so that each individual has the potential to sense every deed they were done. In other words, social reality is the result of a series of interactions between social actors in a particular environment. For interpretive paradigm, science cannot be used to explain and to predict. This is similar to positivism paradigm but rather to understand. Burrell and Morgan (1979) prove that interpretive paradigm is informed by a concern to understand the world as it is, to understand the fundamental nature of the social world at the level of subjective experience. It seeks explanation within the realm of individual consciousness and subjectivity, within the frame of reference of the participant as opposed to the observer of action. The following table is a comparison of the functionalist (positivism) and interpretive paradigm (Table 1).

Burrell dan Morgan (1979) argue that interpretive paradigm consists of several types such as ethnomethodology, phenomenological, and symbolic interactionism. Ethnomethodology is an approach developed in the 1960s, with a unique terminology in which it combines theory, philosophy, and methods. Meanwhile, Mehan and Wood (1975) believe that Ethnomethodology is not a body of findings, nor a method, nor a theory, nor a world view. I considered that Ethnomethodology is a form of life, is an attempt to display the reality of a level which exists beyond the sociological level, it differs from sociology much as sociology differs from psychology.

Phenomenological is a research strategy in which researchers identify the nature of human experience in relation to a particular phenomenon. Understanding human life 
experiences make Phenomenological philosophy as a method of research whose procedures require researchers to have a relatively long and direct study on a number of subjects in order to develop the patterns and relationships of meaning (Moustakas, 1994).

Table 1 - Comparison between the Functionalist (Positivism) and Interpretive Paradigm

\begin{tabular}{|c|c|c|}
\hline $\begin{array}{c}\text { Metatheoretical } \\
\text { Assumptions About }\end{array}$ & Positivism & Interpretivism \\
\hline Ontology & $\begin{array}{c}\text { Person (researcher) and reality are } \\
\text { separate }\end{array}$ & $\begin{array}{c}\text { Person (researcher) and reality are } \\
\text { inseparable (life-world) }\end{array}$ \\
\hline Epistemology & $\begin{array}{c}\text { Objective reality exists beyond the human } \\
\text { mind }\end{array}$ & $\begin{array}{c}\text { Knowledge of the world is intentionally } \\
\text { constituted through a person's lived } \\
\text { experience }\end{array}$ \\
\hline Research Object & $\begin{array}{c}\text { Research object has inherent qualities } \\
\text { that exist independently of the researcher }\end{array}$ & $\begin{array}{c}\text { Research object is interpreted in light of } \\
\text { meaning structure of person's (researcher's) } \\
\text { lived experience }\end{array}$ \\
\hline Method & Statistics, content analysis & Hermeneutics, phenomenology, etc. \\
\hline Theory of Truth & $\begin{array}{c}\text { Correspondence theory of truth: one-to- } \\
\text { one mapping between research } \\
\text { statements and reality }\end{array}$ & $\begin{array}{c}\text { Truth as intentional fulfillment: } \\
\text { interpretations of research object match } \\
\text { lived experience of object }\end{array}$ \\
\hline Validity & Certainty: data truly measures reality & Defensible knowledge claims \\
\hline Reliability & Replicability: research results can be \\
reproduced & $\begin{array}{c}\text { Interpretive awareness: researchers } \\
\text { recognize and address implications of their } \\
\text { subjectivity. }\end{array}$ \\
\hline
\end{tabular}

Source: Sandberg, 2004.

Francis (1982) in his theory explains that symbolic interactionism is essentially a sociological-psychological perspective that is especially relevant for sociological investigations. This theory will deal with social structures, concrete forms of individual behavior or alleged inner qualities. Symbolic interactionism focuses on the nature of the interaction, on the dynamic patterns of social action and social relationships. The interaction itself is considered as a unit of analysis: while the attitudes are put into the background.

Interpretive Research Paradigm in Behavioral Finance. All theories in finance are based on the philosophy of science and the theory of society. Many researchers do not seem to realize or ignore, the philosophical assumptions underlying financial theory. They emphasize only some aspects of the phenomenon and ignore the others unless they come out of the basic philosophical assumptions of the theory.

Each analysis is inseparable from the role of the research paradigm. In social theory, it is understood that there are four key paradigms, namely functionalist, structuralist, radical humanist, and radical functionalist. Those paradigms are found on different views of the social world. Each of which produces different theories, concepts, and analytical tools from each paradigm. These four paradigms are very important to any scientist because the knowledge of the paradigm makes scientists aware of the boundaries in which they approach their subject. Each of the four paradigms implies a different way of social theory in general. Mostly, the financial theories are within the limits of the functionalist paradigm. They abandon other paradigms that are necessary and interesting to investigate.

According to Burrell and Morgan (1979), each theory can relate to one of the four research paradigms. The four paradigms are based on different assumptions about the nature of sciences (the subjective-objective dimension), and the nature of society (the dimensions of radical regulation of change), as presented in Figure 3.

This model of organizational analysis developed by Burrell and Morgan classifies sociological theories along the two orthogonal dimensions of regulation vs. change and subjectivity vs. objectivity (Burrell \& Morgan, 1979). This divides sociology into four fairly distinct paradigm clusters. There is internal consistency under each paradigm, in terms of assumptions about individuals, groups, societies, goals of the study and accepted forms of evidence. However, each cluster neglects, excludes or opposes some the insights generated under other paradigms. 


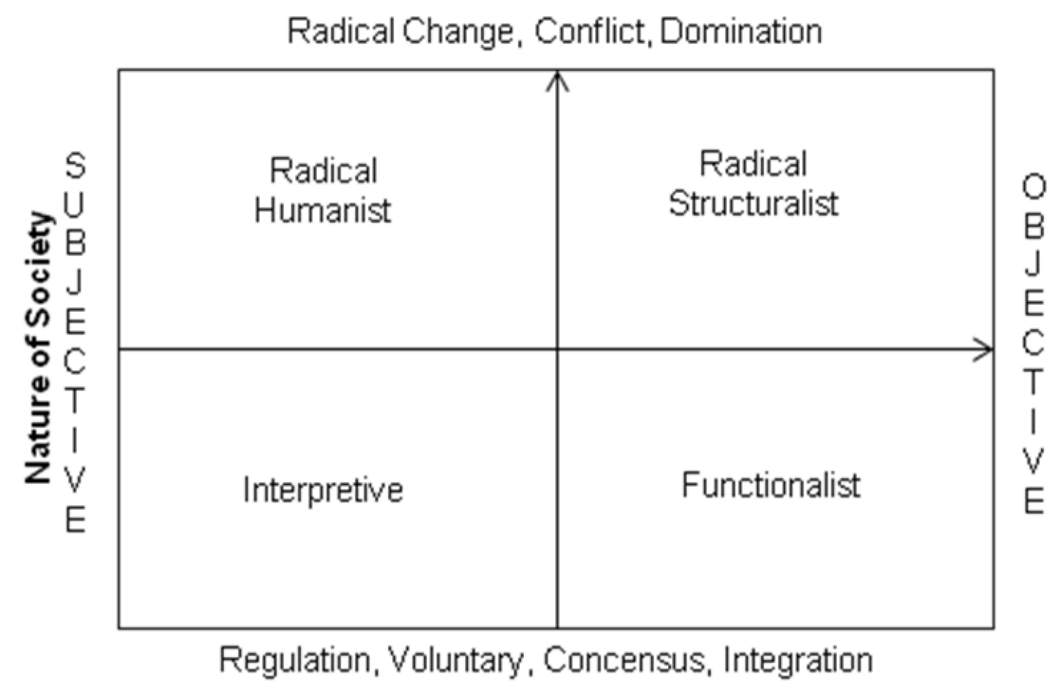

Figure 2 - The Four Paradigms (Burrell and Morgan, 1979)

Burrell and Morgan's model was later taken into social work research, where it was used to define four approaches to understanding the problems of social work clients. This application of the model is illustrated below.

1. Radical Humanist (Change-Subjective): Social opportunities and ideologies are controlled by large social institutions, often leaving people marginalized, voiceless and disempowered, leading to widespread alienation and the breakdown of communities. Interventions are aimed at concrete individuals and groups, establishing mutual aid and consciousness-raising networks that will lead to eventual changes in social and economic structures.

2. Functionalist (Regulation-Objective): Societies are the coming together of populations with shared civic values who establish a social order which on the whole benefits everybody. Individuals and some identifiable groups may fall into misfortune or maladaptive patterns. The goal of intervention is to help them adapt to existing structures, perhaps making minor institutional adjustments where warranted.

3. Radical Structuralist (Change-Objective): Fundamental underlying contradictions and regularities make our entire way of living unjust and untenable. Distressed individuals and groups can be helped to mollify the impact of structural problems, but lasting change can only be achieved by a complete transformation of the society. Intervention must be integrated across political, regional, community and interpersonal levels.

4. Interpretive (Regulation-Subjective): The meaning of social situations is largely a matter of interpretation. Anyone can feel trapped by their situation, but viewing things in a new light can open up new options and lead to better situations. Intervention focuses on helping people reframe events and adjust the maxims they use to regulate their own behavior.

Basically, behavioral finance tries to explain what, why, and how infestation works from a human perspective (Ricciardi and Simon, 2000) so that it is very relevant to use the multiparadigm approach in behavioral finance research particularly the interpretive paradigm. Interpretive paradigm is informed by a concern to understand the world as it is, understand nature from the social world in subjective experience, and explain individuals and subjectivity consciously. This paradigm believes that social reality is consciously and actively built by individuals so that every individual has the potential to interpret every act. In other words, a social reality is the result of a series of interactions between social actors in a particular environment. As for interpretive paradigm, science cannot be used to explain and to predict as well as the functional paradigm but more to understand (Burrel and Morgan, 1979). 


\section{CONCLUSION}

Epistemologically, behavioral finance research raises a controversy which generally uses a functional research paradigm. In this case, it raises the question that why financial research generally uses a functional research paradigm? Whereas there are four research paradigms such as functionalist, radical structuralist, radical humanist, and interpretive. The paradigm of financial research positioned on continuum formed by four basic paradigms so that it is expected that there is another contribution of financial studies by using other paradigms, particularly the interpretive paradigm. Interpretive paradigm consists of several types, such as ethnomethodology, phenomenological, and symbolic interactionism. Those three types of interpretive paradigm can touch the study object that not only depends on its financial market but also on individuals, households, and others so that it has deeper, meaningful, and more diverse research results.

\section{REFERENCES}

1. Ardalan, K. (2003). Theories and controversies in finance: a paradigmatic overview. International Journal of Social Economics, 30(1): 199 - 208.

2. Burrell, G. and Morgan, G. (1979). Sociological Paradigms and Organizational Analysis. Gower, Aldershot.

3. Editorial. (2004). Introduction to the special issue on behavioral finance. Journal of Empirical Finance, 11: 423-427.

4. Francis, M.A. (1982). Modern Sociological Theory (An Interduction). Oxford University press, Oxford.

5. Kahneman, D. (2002). Nobel Lecture. Stockholm, Sweden.

6. Lintner, G. (1998). Behavioral Finance: Why Investors Make Bad Decisions. The Planner, 13(1): 7-8.

7. Mehan, H, and Wood, H. (1975). The Morality of Ethnomethodology. Theory and Society, 2(4): 509-530.

8. Miller, M.H., (1986). Behavioral Rationality in Finance: The Case of Dividends. Journal of Business, 59: 267- 284.

9. Moustakas, C. (1994). Phenomenological Research Methods. Thousand Oaks, CA: Sage.

10. Muradoglu K. and Harvey N. (2012). Behavioural finance: the role of psychological factors in financial decisions. Review of Behavioral Finance, 4(2): 68-80.

11. Olsen, R. (1998). Behavioral Finance and It's Implication for Stock Price Volatility. Financial Analyst Journal, 54(2): 10-18.

12. Ricciardi, V. and Simon, H. (2000). What is Behavioral Finance?. The Business, Education and Technology Journal, 2(1): 26-34.

13. Sandberg, J. (2004). The Rhetoric of Positivism Versus Interpretivism: A Personal View. MIS Quarterly, 28(1): iii-xii.

14. Sasongko, H., Achsani, N., Hasanudin, T.M. (2016). Behavior of Capital Structure and Its Impact on Financial Performance: Empirical Study from Indonesian Listed Mining Sector in 2011-2015. International Journal of Science and Research, 5(11).

15. Shefrin, H. (2000). Beyond Greed and Fear: Understanding Behavioral Finance and Psychology of Investing. Harvard Business School Press.

16. Shiller, R.J. (2003). From efficient markets theory to behavioral finance. Journal of Economic Perspectives, 17(1): 83-104.

17. Spindler, G. (2011). Behavioural Finance and Investor Protection Regulations. Journal of Consumer Policy Consumer Issues in Law, Economics and Behavioural Sciences, 29(1).

18. Thaler, R.H. (Ed.). (1993). Advances in Behavioral Finance. Russell Sage Foundation, New York, NY.

19. Tversky, A. and Kahneman, D. (1979). Prospect Theory: An Analysis of Decision under Risk. Econometrica, 47(2): 263-292. 